International Journal of Medical Sciences

ISSN 1449-1907 www.medsci.org 2006 3(2):69-74

Review

(C)2006 Ivyspring International Publisher. All rights reserved

\title{
Treatment of Chronic HCV Infection in Special Populations
}

\author{
John Hoefs ${ }^{1}$ and Vikramjit S. Aulakh ${ }^{2}$ \\ 1. Division of Gastroenterology and Hepatology, H.H. Chao Comprehensive Digestive Disease Center UCI Medical Center, Orange, \\ CA, USA. \\ 2. Mercy Hospital and Medical Center, 2525 S Michigan Ave, Chicago, Illinois, USA.
}

Corresponding address: John Hoefs, MD, Division of Gastroenterology-hepatology, 101 The City Drive, Building 53, Room 113, Orange, California 92868. Phone: 714-456-6745 and Fax: 714-456-7753

Received: 2005.12.30; Accepted: 2006.03.18; Published: 2006.04.01

The mainstay of treatment of chronic hepatitis $C$ is pegylated interferon combined with ribavirin and more than $50 \%$ of naïve patients will have viral cure with either 6 months (genotypes 2 and 3) or 12 months (genotypes 1,4, and 6) with the initial treatment. However, populations have been defined that respond less well to routine treatment including African Americans, immune suppressed populations, obese patients and cirrhotic patients. These types of patients are enriched in groups of patients who are non-responders to treatment. This article discusses viral kinetics that may impact treatment response, strategies to maximize treatment effectiveness in these populations and the treatment of nonresponders in general. Early viral kinetics can be used to define response or non-response and these results can be used to modify subsequent treatment length and dose.

Key words: $\mathrm{HCV}$, treatment $\mathrm{HCV}$, non-responder, cirrhosis, African American, fatty liver

\section{Introduction}

In the treatment of $\mathrm{HCV}$, the benefits of peg interferon alpha and ribavirin have become clear over the past decade. Where on one hand, this treatment has proven its effectiveness in ideal population; it has also identified some special populations by way of poor response or difficulties faced due to co morbid conditions. These special populations include patients with cirrhosis, non responders to prior treatment, HIV positive patients, patients with African American ethnicity, steatosis, and post liver transplants.

\section{Viral Kinetics.}

Active viral replication in hepatocytes is a hallmark of HCV infection. However, it is likely that viral autoregulation [1] as well as immune factors [2] are important in the control of this infection. Viral auto-regulation is demonstrated by the lack of unlimited viral replication in patients with inhibited immunologic systems and by decrease in the viral RNA level before the emergence of a significant immune response in acute disease [1]. Immunologic factors are important as recovery from acute viral hepatitis is associated with an unopposed TH1 response exposed to $\mathrm{HCV}$ and is also enhanced following treatment, associated with a sustained virologic response (SVR) in Chronic HCV [3]. In general, immune factors prior to treatment or early in treatment do not predict sustained viral response (SVR), defined as negative serum test for HCV RNA 6 months after completion of therapy. Immune factors may be of major importance once the viral load has been sufficiently reduced so that hepatocytes containing the virus are destroyed. The viral kinetic profile (the decrease in viral RNA level with time) in response to treatment can be biphasic or triphasic in the first 4 weeks of treatment. The final phase slope seems to be the most important in determining SVR perhaps related to the death of viral infected hepatocytes [4, 5]. A very early virologic response (VEVR) having a negative RNA at week 4 correlates with the likelihood of an SVR
[5]. Recent studies have shown that viral reduction in the blood in the first 2-4 weeks precedes the immunologic response and may reflect viral reduction below a threshold that allows effective immune attack of infected cells [3]. Furthermore, the mutagenic effect of ribavirin on the NS5A and NS5B regions correlates with an SVR emphasizing the importance of viral factors [6]. Therefore, viral reduction may allow immune clearance rather than immune enhancement causing viral clearance.

$\mathrm{HCV}$ patients can be divided into rapid and slow responders based on viral kinetics (Table 1) [4]. Forty percent of patients were slow responders in one study and this correlated with a positive HCV RNA levels in blood at week 4 . A negative 4 week viral RNA level is sensitive (95\%) and relatively specific (83\%) marker for viral kinetic fast responders [4]. Most patients with a fast response characterized by negative week 4 viral RNA will have an SVR $(90 \%)$ regardless of genotype [4, 7]. This implies that some populations may be treated for short periods of time i.e. 4 months for genotype 2 and 3 [8] and 6 months for genotype 1 [9] depending upon their response to treatment and viral load. Where a negative viral RNA at week 4 predicts an SVR, lack of an early virologic response (EVR), which is defined as a minimum of 2 log decrease in viral load at week 12 of treatment, predicts a non-response with more than $97 \%$ accuracy [5]. Lack of an EVR is an indication that treatment can either be stopped or dose increased. Kinetic analysis also suggests the value of longer treatment if the RNA level becomes negative after 12 weeks [10].

TABLE 1. Viral Kinetics Predict SVR

\begin{tabular}{|c|c|c|c|c|}
\hline & Week 4 RNA & Week 12 RNA & $\begin{array}{c}\text { End of } \\
\text { Treatment }\end{array}$ & SVR \\
\hline VEVR & Negative & Negative & Negative & $90 \% *$ \\
\hline EVR & Positive & $\begin{array}{c}\text { Negative or }< \\
1 / 100 \text { baseline }\end{array}$ & Negative & $70 \%$ ** \\
\hline
\end{tabular}

*May shorten treatment course in genotype 2 to 4 months or genotype 1 with LVL to 6 months with same $\operatorname{SVR}(8,9)$ 
**May lengthen treatment by 3 to 6 months if 12 week RNA still positive to have an increased likelihood of an SVR.

\section{Treatment in African Americans}

Prevalence of HCV in African Americans is about 3 times greater than Caucasians [11]. The problems of HCV infected African Americans are that they are more likely to be infected with genotype 1 , more likely to have $\mathrm{HCV}$ complications, have higher rate of cirrhosis, HCC and death due to HCV[12].

The 4 week log reduction in viral RNA was seen to be less in African Americans than Caucasians by 50\%. This indicates a larger population of slow responders in African Americans which may explain a low SVR in this population compared to other groups [13]. African American patients showed significantly lower decrease in HCV RNA over the first 24 hours than Caucasians and significantly longer delay in initial response and significant difference in the rate of loss of virus producing cells [13]. Various studies have ruled out other explanations including lack of adherence and dose reduction due to poor tolerance or low baseline neutrophils, for the poor response. In fact, a larger percentage of African Americans completed the therapy in some of these studies compared to other racial groups despite a greater reduction in neutrophils as anticipated with the low baseline levels [13]. Despite greater compliance and similar side effect profile, the SVR was decreased in African Americans relative to other groups [11]. Regardless, combination therapy with interferon alpha and ribavirin remains the treatment of choice for African Americans with chronic HCV [11].

The lack of suppression by treatment should be amendable to higher dose treatment or prolonged therapy once viral suppression is adequate. Though this has not been studied directly in the African American population, it has been studied in non responders and relapsers to prior monotherapy.

\section{Immune Suppressed Populations - post liver transplant or HIV infection}

Immune suppressed patients have a higher baseline RNA level and more rapid progression to cirrhosis [14, 15]. The increase in RNA level supports the importance of what appears to be a relatively weak, ineffective immune response since it is inadequate to clear the virus. Since immunologic mediated inflammation is thought to be the mechanism of progressive fibrosis, it is surprising that immune suppression does not ameliorate the disease at the expense of higher viral levels. The exact relationship of immune suppression to progression of fibrosis is unclear, but suggests there may be a differential effect on lymphocyte sub-populations $[16,17,18]$.

In HIV positive patients with $\mathrm{HCV}$, the rate of fibrosis and rate of progression to cirrhosis or decompensation ( $R R=2.92,95 \%$ CI $1.70-5.01)$ is markedly increased particularly with reduced CD4 counts [19]. Chronic liver disease has become the most common cause of death in adequately treated HIV patients [20]. Evidence for more rapid progression can also be found in HCV patients with recurrence after liver transplant with > $10 \%$ having cirrhosis within 5 years $[18,21]$. Patients transplanted for HCV eventually have significantly reduced survival relative other transplant groups primarily related to recurrent cirrhosis.
The treatment of these two immunologically suppressed cohorts are complicated since both are on multiple drugs with potential for interactions or hepatotoxicity and which may have independent effects on bone marrow suppression. Close monitoring is required along with treatment of cytopenias, dose reduction, and dose discontinuation (20-30\%) in the management of these patients. Interferon monotherapy and interferon alpha $2 \mathrm{~b}$ plus ribavirin have low response rates (10-30\% and $20-30 \%$, respectively) [15]. Pegylated interferons plus ribavirin (usually in reduced dose of 800 $\mathrm{mg}$ /day) have higher response rates than these latter two options (30-45\%) [15]. The early viral kinetics in these patients is similar to unsuppressed patients with higher viral loads baseline. The lack of EVR is equally predictive of NR $(98 \%)$ allowing a decision to stop treatment if this criteria is not met [15].

\section{Cirrhotics}

Treatment of non-decompensated cirrhotics is important since they have reduced survival, increased incidence of HCC and progression to a decompensated state with ascites and GI bleeding [19]. The goal of therapy is to prevent progression of liver disease to these poor clinical outcomes. An SVR has been shown to reduce these unfavourable outcomes by at least $50 \%$, but even a treatment course without a durable virologic response appears to reduce these complications [13, 20]. These latter studies have led to clinical protocols of low dose maintenance treatment in which the goal of therapy is changed from viral cure to prevention of disease progression. Clearly, treatment is strongly indicated with early cirrhosis without decompensation as progression will occur in the majority of patients. Treatment is more difficult in the setting of decompensated cirrhosis although this can produce an SVR in $20-25 \%$ of patients [22].

The SVR for naïve compensated cirrhotic patients is $30-45 \%$ compared to $50-55 \%$ in non-cirrhotics. Potential explanations for the reduced SVR could be inherently poor virologic response with a decrease in the week 4 reduction and intolerance of treatment requiring dose reduction. Clearly, genotype 2 or 3 and low viral load predict better results [23]. In a small study, cirrhotics did not have slow response characteristics which predict nonresponse. The major problem appears to be relapse once medication is stopped. These patients may respond to longer treatment once the viral levels have become negative although this has not been studied.

Retreatment of cirrhotics with pegylated interferon and ribavirin is also associated with a poor SVR (6-12\%) [23]. A low response was found in the retreatment with pegylated alpha 2a plus ribavirin in cirrhotics (12\% SVR) compared to non-cirrhotics ( $20 \%$ SVR) in lead in phase of the HALT-C trial [23]. The initial publication from this trial concluded that ribavirin dose reduction affected the SVR more than interferon reduction [23] although dose discontinuation was lumped together with dose reduction. Subsequent analysis showed that patients with dose continuation (primarily ribavirin) had virtually no SVR $(1.3 \%)$. In the rest, ribavirin reduction to $<60 \%$ of target dose did not affect SVR (17\%) as long as pegylated interferon dose was not reduced.

These patients were further divided into 4 cohorts of liver disease severity based on the histologic cirrhosis and platelet count $<$ or $>125,000$ cell/mm3 [24]. Those in the 
best cohort (non-cirrhotic with platelets > 125,000 cells $/ \mathrm{mm} 3$ ) had an SVR of $17 \%$ compared to $7-8 \%$ in the cirrhotic groups. In the non-cirrhotic patients, dose reduction (without discontinuation) had no impact on the SVR whereas there was a nearly significant effect in cirrhtoics (12\% with full dose vs 7-8\% for dose reduction; $p=.058$ ). Further support for liver disease severity being the most important factor in the non-response of cirrhotic patients was provided in an ancillary study of quantitative liver functions tests that included cholate shunt and clearance, perfused hepatic mass (PHM) by quantitative liver spleen scan, and aminopyrine breath test showed that the most severe quartile of these patients had an SVR of $2 \%$ compared to $17 \%$ in the other quartiles [25]. Severity of liver disease impacts response to treatment directly rather than primarily through dose reduction or intolerance.

\section{Fatty Liver}

Fatty liver predicts a lower SVR regardless of other factors in both primary treatment (SVR $40-50 \%$ vs $50-55 \%$ without steatosis) and re-treatment of non-responders with pegylated interferon plus ribavirin (SVR 10-20\% with vs $20-30 \%$ without) [26]. In pegylated interferon $2 b$, weight based dosing have been suggested as an important factor. Weight based dosing is dependent on pharmokinetics. It is required for Pegylated alpha $2 b$ and not for alpha 2a. There is a decrease in SVR in patients with a fatty liver to a similar degree with both products using the recommended doses [27]. The weight based dosing with Peg alpha $2 b$ does not produce better results in patients with fatty liver.

\section{Re-treatment of non-response}

Naïve patients initially treated with interferon monotherapy have a low response rate that is improved by longer treatment from 24 to 48 weeks [28]. Retreatment with peginterferon plus ribavirin will produce SVR of $28 \%$ [23]. Even patients initially treated with pegylated interferon monotherapy have a $20 \%$ SVR to retreatment with pegylated combination therapy [29]. Therefore, re-treatment with peginterferon plus ribavirin should be considered in non-responders or relapsers to interferon monotherapy.

The effect of longer treatment as a principal can be seen in the initial studies with interferon monotherapy in which the SVR increased from 6\% with 6 months of treatment to $12 \%$ with 12 months $[5,30]$. Additional evidence comes in the studies of patients treated with PEG interferon plus ribavirin for 6 months with relapse, who were then treated for 12 months with a 50\% SVR. Those people with viral suppression during treatment may benefit from stronger and longer treatment [5].

Table 2 shows the SVR in re-treatment of patients who were non-responders to combination therapy with regular interferon and ribavirin. The SVR ranges from 4$12 \%$ with responses greater with genotypes 2 and 3 . The effect of longer treatment has not been tested. Nonresponders to Peg-interferon plus ribavirin have exhausted our routine relatively tolerable therapy. However, dose induction studies attempt to maximize viral RNA suppression by early higher dose treatment protocols which are often somewhat longer as well. Protocol includes ribavirin plus peginterferon alpha $2 \mathrm{a}$ at 270 or $360 \mu \mathrm{g}$ per week and consensus interferon with 27 , 18 and $9 \mu \mathrm{g}$ daily [31].
TABLE 2. Retreatment of IFN + RBV failures with PEG-IFN $+\mathrm{RBV}$

\begin{tabular}{|c|c|c|c|}
\hline Investigator & Patients & Study Drug/Dose & SVR \\
\hline $\begin{array}{c}\text { Teuber G, et al. DDW. } \\
2003\end{array}$ & 240 & $\begin{array}{c}\text { PEG-IFN a-2b } \\
100 \mu \mathrm{g}+\text { RBV } 800 \\
\text { mg } \times 8 \mathrm{wk}, \mathrm{PEG}- \\
\text { IFN a-2b } 50 \mu \mathrm{g}+ \\
\text { RBV } 800 \mathrm{mg} \times 40 \\
\text { wk }\end{array}$ & $6.3 \%$ \\
\hline $\begin{array}{l}\text { Jacobson I, et al. } \\
\text { DDW } 2003\end{array}$ & 219 & $\begin{array}{l}\text { PEG-IFN a-2b } 1.0 \\
\mu \mathrm{g} / \mathrm{kg}+\mathrm{RBV} 1- \\
1.2 \mathrm{~g} \times 48 \mathrm{wk} \\
\mathrm{PEG}-\mathrm{IFN} \mathrm{a}-2 \mathrm{~b} 1.5 \\
\mu \mathrm{g} / \mathrm{kg}+\mathrm{RBV} 800 \\
\mathrm{mg} \times 48 \mathrm{wk}\end{array}$ & $\begin{array}{c}6 \% \\
10 \%\end{array}$ \\
\hline $\begin{array}{c}\text { Sulkowski M, et al. } \\
\text { DDW } 2003\end{array}$ & 517 & $\begin{array}{l}\text { PEG-IFN a-2b } 1.5 \\
\mu \mathrm{g} / \mathrm{kg}+\mathrm{RBV} \\
800 \mathrm{mg} \times 48 \mathrm{wk} \\
\text { PEG-IFNa-2b } \\
100 / 150 \mu \mathrm{g}+\mathrm{RBV} \\
800 \mathrm{mg} \times 48 \mathrm{wk}\end{array}$ & $12 \%$ \\
\hline $\begin{array}{c}\text { Lawitz E, et al. DDW } \\
2003\end{array}$ & 486 & $\begin{array}{c}\text { PEG-IFN a-2b } 1.5 \\
\mu \mathrm{g}+\text { RBV } 800 \mathrm{mg} \\
\mathrm{x} 48 \mathrm{wk}, \mathrm{PEG}-\mathrm{IFN} \\
\mathrm{a}-2 \mathrm{~b} 1.0 \mu \mathrm{g} / \mathrm{kg}+ \\
\text { RBV } 800 \mathrm{mg} \mathrm{x} \\
36 / 48 \mathrm{wk}\end{array}$ & $5-10 \%$ \\
\hline $\begin{array}{c}\text { Gross JB et al, AASLD } \\
2003\end{array}$ & 764 & $\begin{array}{c}\text { PEG-IFN a } 2 \mathrm{~b} \\
0.5 / 1.5 / 3 \mu \mathrm{g} / \mathrm{kg} \\
\mathrm{RBV} 12-15 \mathrm{mg} / \mathrm{kg} \\
\times 48 \mathrm{wk}\end{array}$ & $4-11 \%$ \\
\hline $\begin{array}{l}\text { Shiffman ML et al } \\
\text { Gastroenterology } \\
2004\end{array}$ & 210 & $\begin{array}{c}\text { PEG-IFN a } 2 \mathrm{a} 180 \\
\mu \mathrm{g}+\text { RBV } 1-1.2 \mathrm{~g} \mathrm{x} \\
48 \mathrm{wk}\end{array}$ & $12 \%$ \\
\hline
\end{tabular}

Re-treatment has not been investigated directly in large numbers of patients with co-infection, fatty liver or cirrhosis. However, the non-responder re-treatment trials are enriched with these patients as are the lead-in phase of the some of the maintenance studies. Furthermore, some trials now define non-responder as early as 12 or even 4 weeks modifying treatment with either stronger treatment or longer treatment to try to produce a better SVR $[7,32]$.

\section{Longer treatment}

Kinetic studies suggest potential value for large treatment in patients who slowly become RNA negative, particularly in genotype 1 patients [10]. A study by Sanchez-Tapias et al [7] treated patients with a pegylated alpha 2a plus ribavirin (1000 or $1200 \mathrm{mg}$ ) for 4 weeks. Preliminary data in abstract form showed those patients that have a negative RNA by PCR ( $40 \%$ of cohort) continued treatment for either 6 or 12 months depending on genotype with SVR of $92 \%$. Those patients who were RNA positive were randomized to either a total of 48 weeks or 72 weeks followed by RNA levels 6 months after stopping with SVR of 35 and $50 \%$ respectively $(p<.001)$. Slower responders benefit from longer treatment.

\section{Stronger treatment}

Induction studies have treated patients with nonresponse and relapse with higher

Doses of Consensus or pegylated interferons for the first 1-12 weeks followed by continued high dose or return to more normal treatment regimes. Retreatment under a variety of protocol conditions have achieved SVR from 25$40 \%$ in patients with expected response rates of $1-12 \%$. Most of the results from these very interesting studies are published in abstract form and we are waiting the publication of the full articles.

A study by Kaiser, et al [31] of induction dosing with daily Consensus interferon and Ribavirin $(11 \mathrm{mg} / \mathrm{kg} /$ day $)$ starting after week 4 . Thirty patients in group A received 
27 ug SC daily for 4 weeks followed by 18 ug daily for 12 weeks and the second group B of 30 patients received 9 ug SC daily for 16 weeks. At the end of 16 weeks, all patients were treated with 9 ug SC daily until the patient had been HCV RNA negative for 48 weeks. RNA was negative at 24 weeks in $47 \%$ and $40 \%$, respectively, and at the end of treatment in $50 \%$ and $43 \%$. The SVR was $27 \%$ in group A and $23 \%$ in group B. Adverse events, dose discontinuation (10 vs $3 \%$ ) and dose reduction (23 vs $10 \%$ ) were similar to conventional therapy. All patients were treated longer than 48 weeks (if treatment was not stopped) and the average was 60 weeks.

One study by Leevy, et al [33] treated patients with peg interferon alpha $2 \mathrm{~b}(1.5 \mathrm{ug} / \mathrm{kg}$ weekly) and weight based ribavirin (1000-1200 mg per day) for 3 months. Patients without an EVR were then treated with consensus interferon 15 ug daily for 3 months followed by $15 \mathrm{ug}$ TIW for the remainder of treatment for a total of 15 months of treatment. RNA negativity at 12, 24 and 48 weeks was 23,31 and $43 \%$. SVR was $37 \%$ overall and 27 $\%$ in AA compared to $41 \%$ in non-AA. This study mimics the situation in clinical practice in which failure during therapy is followed by the decision to treat with higher dose or to stop treatment as ineffective. Despite fatigue and tiredness in nearly all patients and a decrease in ANC to $<750$ cells $/ \mathrm{mm} 3$ in $22 \%$, no patients stopped treatment.

A small study (75 patients) by Diago et al [34] assessed induction dose with pegylated interferon alpha $2 \mathrm{a}$ in three cohorts of genotype 1 patients who were nonresponders to regular interferon alpha $2 b$ plus ribavirin. All patients were treated for 44 weeks with $180 \mu \mathrm{g}$ pegylated alpha $2 \mathrm{a}$ and ribavirin after an initial 4 week induction dose of 180, $270360 \mu \mathrm{g}$ per week ( total treatment of 48 weeks). The SVR was $18 \%, 30 \%$ and $38 \%$ in the respective groups. Gitlin et al [35] reported results in patients with non-response to pegylated alpha $2 \mathrm{~b}$ plus ribavirin. The SVR in response to retreatment with pegylated alpha 2 a plus ribavirin was $32 \%$ overall with $27 \%$ in cirrhotics and $14 \%$ in African Americans.

The results of RENEW trial of induction dosing using pegylated alpha $2 \mathrm{~b}$ plus ribavirin in 650 interferon alpha $2 \mathrm{~b}$ plus ribavirin non-responders were less encouraging. The SVR to $0.5 \mu \mathrm{g} / \mathrm{kg}, 1.5 \mu \mathrm{g} / \mathrm{kg}$ and $3 \mu \mathrm{g} / \mathrm{kg}$ was $4 \%, 7 \%$ and $11 \%$ respectively [36]. However, the TARGET trial of $3.0 \mu \mathrm{g} / \mathrm{kg}$ of pegylated alpha $2 \mathrm{~b}$ plus ribavirin showed SVR of $14 \%$ [37].

In conclusion, higher dose and induction dosing seems to produce acceptable salvage SVR in patients who are non-responders to prior combination therapy.

\section{Recommendations}

In naïve patients in special populations, the treatment can be started off with regular dose of pegylated interferon and weight based dosing for ribavirin. However, since these populations in general have a lower response rate, it seems reasonable to modify dosage or length of treatment based on $4^{\text {th }}$ and $12^{\text {th }}$ week viral RNA level. Patients with genotype 2 or 3 and genotype 1 with low viral load who became negative for viral RNA at week 4 , may have a shorter length of treatment of 4 months and 6 months respectively without sacrificing the SVR.

In patients who are RNA positive at week 4 and do not meet the EVR criteria at week 12, then the treatment can be stopped or considered for dose escalation with pegylated interferon or daily dosing with infergen. If Viral RNA is positive at week 4 but meets EVR at week 12, medication should be continued. If HCV RNA by PCR is not negative by month 6 , then treatment can be stopped or considered for dose escalation. But if it does become negative by month 6 , it seems reasonable in this group of difficult to treat patients to treat for 72 months total as long as RNA remains negative. The role of maintenance treatment in these special groups of non-responders is not clear, but should be considered in those with moderate fibrosis or cirrhosis.

\section{Conflict of interest}

The first author declared that the only potential conflict of interest is prior relationship to Roche as a speaker. None declared for the second author.

\section{References}

1. Sallie R. Replicative Homeostasis: A fundamental mechanism mediating selective viral replication and escape mutation. Virol J. 2005; 2: 10-23

2. Chisari FV. Unscrambling hepatitis $C$ virus-host interactions. Nature 2005; 436(7053): 930-2

3. Bowen DG, Walker CM. Adaptive immune responses in acute and chronic Hepatitis C virus infection. Nature 2005; 436(7053): 946-52.

4. Tang $\mathrm{KH}$, Herrmann $\mathrm{E}$, et al. Relationship between early HCV kinetics and T-cell reactivity in Chronic Hepatitis $\mathrm{C}$ genotype 1 during peginterferon and ribavirin therapy. J Heptol. 2005; 43(5): 776-82

5. Ferenci P. Predicting the therapeutic response in patients with chronic hepatitis C: the role of viral kinetic studies. Journal of Antimicrobial chemotherapy, 2004; 53:15-18

6. Asahina $\mathrm{Y}$, Izumi $\mathrm{N}$ et al. Mutagenic effects of ribavirin and response to interferon/ribavirin combination therapy in chronic hepatitis C. J Hepatol. 2005; 43(4): 623-9.

7. Sanchez-Tapias JM et al. Sustained virological response after prolonged treatment with peginterferon alfa-2a (40KD) and ribavirin in treatment- naïve patients with chronic hepatitis $\mathrm{C}$ and detectable HCV RNA after week 4 of therapy: TERAVIC-4 study. In: Poster abstracts presented at 39th Annual Meeting of the European Association for the Study of the Liver; April 14-18, 2004; Berlin, Germany

8. von Wagner $M$, Huber $M$, Berg $T$ et al. Peginterferon alpha 2a (40KD) and ribavirin for 16 or 24 weeks in patients with genotype 2 or 3 chronic hepatitis C. Gastroenterology. 2005; 129(2): 522-7

9. Zeuzem S, Buti M, Ferenci P, el al. Efficacy of 24 weeks treatment with peginterferon alfa-2b plus ribavirin in patients with chronic hepatitis $C$ infected with genotype 1 and low pretreatment viremia. J Hepatol. 2006;44(1):97-103.

10. Drusano GL, Preston SL. A 48-week duration of therapy with pegylated interferon alpha $2 \mathrm{~b}$ plus ribavirin may be too short to maximize long-term response among patients infected with genotype-1 hepatitis C virus. J Infect Dis. 2004;189(6):964-70.

11. Bacon BR, McHutchison JG. Treatment issues with chronic hepatitis C: special populations and pharmacy strategies. Am J Manag Care. 2005;11:S296-306

12. Howell C, Jeffers L, Hoofnagle JH. Hepatitis C in African Americans: summary of a workshop. Gastroenterology. 2000;119:1385-1396.

13. Jeffers LJ, Cassidy W, Howell CD, et al. Peginterferon alfa-2a (40 kd) and ribavirin for black American patients with chronic HCV genotype 1. Hepatology. 2004;39:1702-1708.

14. Heathcote EJ, Pockros PJ, Fried MW, et al. The pharmacokinetics of pegylated-40K interferon alfa-2a (PEG-IFN) in chronic hepatitis $\mathrm{C}$ (CHC) patients with cirrhosis. Gastroenterology. 1999;116(4):737.

15. Torriani FJ, Rodriguez-Torres M, Rockstroh JK. Peginterferon alfa-2a plus ribavirin for chronic hepatitis $\mathrm{C}$ virus infection in $\mathrm{HIV}$-infected patients. N Engl J Med. 2004;351(5):438-450.

16. Graham CS, Baden LR, Yu E. Influence of human immunodeficiency virus infection on the course of hepatitis $C$ virus infection: a metaanalysis. Clin Infect Dis. 2001;33:562-569. 
17. Lindsay KL, Trepo C, Heintges $\mathrm{T}$, et al. A randomized, double-blind trial comparing pegylated interferon alfa- $2 b$ to interferon alfa- $2 b$ as initial treatment for chronic hepatitis C. Hepatology. 2001;34:395-403.

18. Terrault NA. Treatment of recurrent hepatitis $C$ in liver transplant recipients. Clinical Gastroenterol Hepatol. 2005; 10:S125-31

19. Lee W, Dieterich D. Challenges in the management of HIV and hepatitis C virus infection. Drugs. 2004;64(7):693-700

20. Bica I, McGovern B, Dhar R, et al. Increasing mortality due to endstage liver disease in patients with Human Immunodeficiency Virus infection. Clin Infect Dis. 2001;32:492-497.

21. Oldakowska-Jedynak U, Paczek L. The course of hepatitis C infection after liver transplantation. Pol Merkuriusz Lek. 2005; 19(110): 220-4.

22. Everson GT, Trotter J, Forman L, Kugelmas M, Halprin A, Fey B, Ray C. Treatment of advanced hepatitis $C$ with a low accelerating dosage regimen of antiviral therapy. Hepatology. 2005;42(2):255-62

23. Shiffman ML, Di Bisceglie AM, Lindsay KL. Peginterferon slfa-2a ribavirin in patients with chronic hepatitis $C$ who have failed prior treatment. Gastroenterology. 2004;126:1015-1023.

24. Everson E, Schiffman M, Hoefs J, et al. Quantitative liver function tests predict sustained virologic response to retreatment with peginterferon alfa-2a plus ribavirin: results of the lead-in phase of the halt-C trial. Hepatology 2004; 40:313A.

25. Everson E, Hoefs J, Malet P. Impaired virologic response in patients with advanced liver disease due to chronic hepatitis $C$ is independently linked to severity of disease: results from the Halt $\mathrm{C}$ Trial. Hepatology 2004; 40: 180A.

26. Harrison SA, Brunt EM, Oliver DA, et al. The presence of severe steatosis or steatohepatitis impairs response to antiviral therapy in patients with chronic hepatitis C. Hepatology. 2003;38(1):A626.

27. Bruno $R$, Sacchi $P$ et al. Viral dynamics and pharmacokinetics of peginterferonalpha-2a and peginterferon alpha- $2 \mathrm{~b}$ in naïve patients with chronic hepatitis C: a randomized, controlled study. Antivir Ther. 2004; 9(4): 491-7

28. Enriquez J, Gallego A, Torras X, Perez-Olmeda T, Diago M, Soriano V, Lujan MS, Garcia-Samaniego J. Retreatment for 24 vs 48 weeks with interferon-alpha2b plus ribavirin of chronic hepatitis $C$ patients who relapsed or did not respond to interferon alone. J Viral Hepat. $2000 ; 7(6): 403-8$.

29. Sethi A, Shiffman ML. Approach to the management of patients with chronic hepatitis $\mathrm{C}$ who failed to achieve sustained virologic response. MD consults core collection. Clinics in Liver Disease 2005; 9: 453

30. Horvath G, Stotz $G$ et al. The effect of long term and high dose interferon treatment in chronic hepatitis C. Pathol Oncol Res. 1996;291: 59-62

31. Kaiser $S$ et al. Successful retreatment of chronic hepatitis $C$ patients with a nonresponse to standard interferon/ribavirin using daily consensus interferon and ribavirin. In: 55th AASLD Abstract 173 (poster); October 29-November 2, 2004; Boston, MA.
32. Dimarco V, Vaccaro A, Ferraro D et al. High dose prolonged combination therapy in non-responders to interferon monotherapy for chronic hepatitis C. Alimentary pharmacology and therapeutics 2001,15: 953-958

33. Leevy CB, Chalmers CP et al. Comparison of African American and Non African American patients SVR for PEG-IFN alpha $2+$ weight based ribavirin non-responders retreated with IFN alpha + weight based ribavirin. In: AASLD Abstract 172; Oct 29- Nov 2, 2004; Boston, Massachusetts.

34. Diago et al. High dose peginterferon alfa 2a (40KD) and ribavirin in patients infected with hepatitis $C$ virus genotype 1 who failed to respond to interferon alfa and ribavirin. Abstract Hepatology, 2003, 38: 740-741

35. Gitlin N, Muther KD. Sustained viral response with peginterferon alpha $2 \mathrm{a}$ and ribavirin in patients with chronic hepatitis $C$ who were non-responders to peginterferon alpha $2 \mathrm{~b}$ and ribavirin. In: AASLD (Abstract 413); Oct 29- Nov 2 2004; Boston, MA.

36. Gross JB et al. Renew Trial- High dose re-treatment with peginterferon alpha $2 \mathrm{~b}$ plus ribavirin for non responders in chronic HCV patients. In: AASLD 2003 (Abstract 321); Oct 24-28 2003; Boston , MA.

37. Malet $\mathrm{P}$, et al. The Target Trial- Final result using $3.0 \mu \mathrm{g} / \mathrm{kg}$ pegylated Interferon alpha $2 \mathrm{~b}$ plus ribavirin for chronic hepatitis $\mathrm{C}$ patients who were non-responders and relapsers to previous therapy. In: AASLD presentation; Nov 15 2005; CA, US.

\section{Author biography}

John Hoefs has been involved in research at the University of California Irvine where he has been Director of the Liver Disease Program for more than 25 years. He reported the mathematic model for colloid osmotic pressure and hydrostatic balance into the peritoneal cavity and the use of the serum to ascites albumin gradient (SAAG) in the differential diagnosis of ascites. Much of his research and clinical effort has been in the developing of a non-invasive evaluation of liver function using the quantitative liver-spleen scan and the treatment of chronic hepatitis C. He was involved in many of the early studies (since 1989) of interferon mono-therapy, consensus interferon trials, Rebetron combination therapy and treatment studies with pegylated alpha-2-b combination treatment. Most recently, the University of California Irvine has been one of the sites of the HALT-C trial. Thus, he has a large clinical experience with chronic hepatitis $C$. Vikramjit S. Aulakh: Dr Aulakh is a resident at Mercy Hospital and Medical Center in Chicago, Illinois. He served in a research preceptorship at the University of California Irvine. 


\section{Figure}

Figure 1. Approach to the Chronic Hepatitis C Treatment in difficult to treat patients

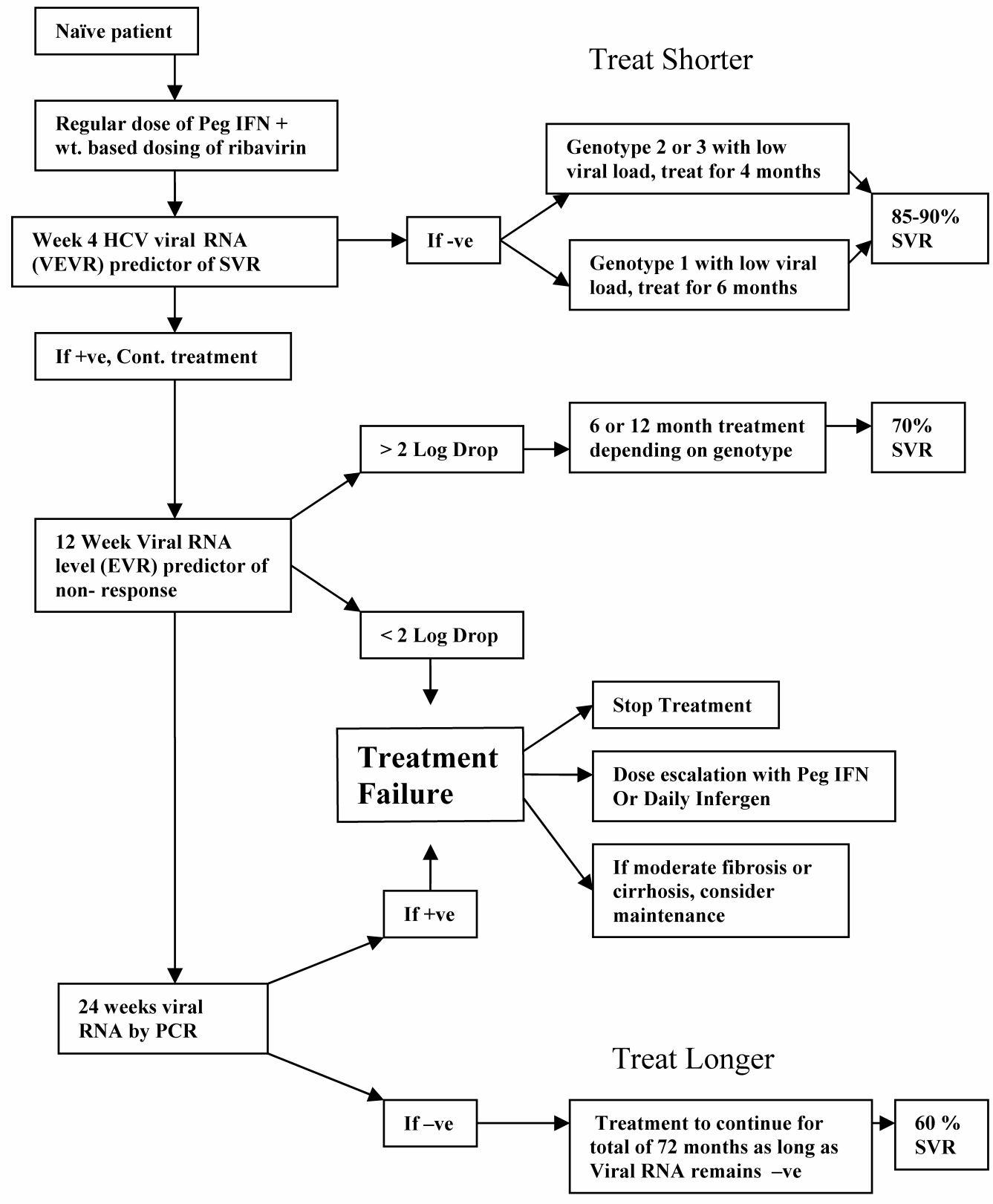

